\title{
El agua y su legislación. Acuerdos y confli ctos en los Valles Centrales de Oaxaca (México), en la transición del siglo XIX al siglo XX ${ }^{1}$
}

Water and its legislation. Agreements and conflicts in the Central Valleys of Oaxaca (México), in the transition from the nineteenth to the twentieth century

\section{Antonio Escobar Obmstede}

Centro de Investigación y Estudios Superiores en Antropologia Social, México

ohmstede@ciesas.edu.mx

http://orcid.org/0000-0002-8955-6966

Olivia P. Topete Pozas

Instituto de Investigaciones Históricas de la Universidad Nacional Autónoma de México, México

olistopes@hotmail.com

\section{Resumen:}

Se considera que las leyes, decretos y bandos influían o marcaban normas en las sociedades rurales y urbanas; lo cual es parcialmente cierto. Sin embargo, poco se ha analizado cómo esas leyes se nutren de las normas y derechos ejercidas por diversos actores sociales, y cómo a su vez fueron utilizadas en las tensiones sociales. En este artículo, mostramos cómo en los Valles Centrales de Oaxaca, los diversos actores sociales se ajustaron o pretendieron modificar su acceso, manejo, control y administración del agua en la transición del siglo XIX al siglo XX.

Palabras Clave: Agua, Legislación, siglos XIX y XX, Oaxaca.

\section{Abstract:}

Laws, decrees and sides are considered to influence or set standards in rural and urban societies; which is partially true. However, little has been analyzed how these laws are based on the norms and rights exercised by various social actors, and how they were in turn used in social tensions. In this article, we show how in the Central Valleys of Oaxaca, the various social actors adjusted or intended to modify their access, management, control and water management in the transition from the nineteenth to the twentieth century.

KEYWORDS: Water, Legislation, XIX and XX centuries, Oaxaca.

\section{INTRODUCCIÓN}

Los estudios de cómo se ha accedido, manejado, controlado y administrado al agua, como un recurso de vital importancia para los seres vivos, nos enfrentan a discusiones en diversos niveles y planos, que abarcan lo ambiental, lo agrario y lo social en la historia. Si bien hoy en día se presentan procesos sociales, económicos y políticos vinculados con el agua, consideramos que es importante comprender las distintas interconexiones que se dan entre los diversos actores sociales, sobre todo en un momento histórico en México en que se da no solo la transición de siglos, sino las implicaciones sobre los cambios de un tipo de derecho administrativo al positivo.

Por otra parte, los hechos históricos no se dan por sí solos, el conocimiento cotidiano que se crea generación tras generación, en muchas ocasiones se refleja en lo que la legislación marca -al menos en términos regionales-; no debe pensarse que el orden es siempre jerárquico, desde arriba hacia abajo únicamente, más

\section{Recepción: 03 Diciembre 2019 | Aceptación: 06 Julio 2020 | Publicación: 01 Diciembre 2020}


bien considérese la conformación de corpus legales, que en muchos casos se nutren de las propias realidades y prácticas -cargadas de usos y costumbres, tiempo inmemorial-, las que se pretenden ordenar desde "arriba" a través de leyes, reglamentos y decretos, con el fin de evitar se continúe el "desorden” que pudieran percibir los magistrados, juristas, grupos de poder, economicistas, etc. ${ }^{2}$ En este sentido, como bien lo mencionan Olivia Topete y Armando Méndez, retomando un texto de Rosa Congost (2007), es necesario tomar en cuenta que "las decisiones legislativas emprendidas por un Estado no siempre tienen el mismo efecto ni el mismo sentido, por lo que pueden crear nuevas tensiones y conflictos en el campo de las fuerzas reales" (Topete y Méndez, 2019 , p. 59). Continuando con la idea, tenemos que "desacralizar" el concepto de propiedad de la tierra y de los recursos naturales en general, a fin de evitar caer en una historia lineal o en una "sobrevaloración a menudo inconsciente" del fenómeno, del Estado nacional y de la importancia de las leyes, lo que nos puede llevar a un juridicismo que subordina a la historia social (Congost 2007, pp. 11-35 y pp. 28-31); aun así, deseamos insistir en observar cómo las leyes emanadas desde los gobiernos de los estados de la federación, en México pueden ser vistos como ajustes a las demandas regionales.

Con base en la anterior, nos sumamos a una historiografía revisionista, la que en mucho ha retomado los trabajos de Rosa Congost. Bajo los análisis de esta autora se han ido realizando diferentes estudios sobre los derechos de propiedad (agua, tierra, bosques), en los que las "prácticas y usos de éstos son una continua construcción y producto de las relaciones sociales" (Congost, 2007, p. 15). Estas investigaciones ponen sobre la mesa una amplia gama de formas y maneras de derechos sobre los bienes, los cuales en muchos casos se sobreponen incluso con elementos de un pluralismo jurídico. Hablamos de distintos tipos de derechos y dominios; conceptos e ideas que aún se nos deslizan en términos conceptuales, pero que se presentan en momentos de tensiones sociales. ${ }^{3}$

Sin embargo, con el fin de distanciarnos del dualismo humano(s)-naturaleza(s) -pero sin dejar de ser conscientes de los cambios que se dan-, y observando el conflicto no solo como aquel que se presenta únicamente entre dos actores (p. e. Rosas, 2018; Arrioja, 2012, p. 185), debemos aventurarnos a recapacitar en lo que implican los intermediarios políticos, sociales y económicos, los que diluyen el dualismo de las tensiones sociales, al canalizar las diferencias por "vías institucionales", aunque no siempre acertadas ( $\mathrm{p}$. e. Barcos, Lanteri y Merino (dirs), 2017). Incluso, consideremos las identidades colectivas, las identidades políticas e individuales que permiten, en ciertos momentos, que los actores sociales compartan vínculos preexistentes o construidos por ellos para obtener una meta común con la cual se comprometen.

De aquí que el objetivo principal de este artículo sea mostrar los ajustes y continuidades que se realizaron a la legislación sobre las aguas, y comprender el papel de los diversos actores sociales en el manejo, acceso, control y administración del agua en los Valles Centrales de Oaxaca (México), así como las negociaciones que se dieron a través de las diferencias y de los acuerdos en torno a dicho recurso. Los ajustes, en muchos casos, reflejaron las formas en que los distintos actores presentaron y esgrimieron sus argumentos para tener derecho al agua. Sin duda, estos derechos y testimonios se manifestaron en las diversas disputas, negociaciones y vivencias cotidianas en torno a un recurso central para la sobrevivencia de humanos, animales y semillas, lo que en muchos casos se remonta al periodo colonial. (Martín, 2018, pp. 33-68; Arrioja y Sánchez (eds.), 2012), además de ser la "materia prima" que permitió incrementar los procesos de industrialización.

Bajo la óptica anterior, y la de las distintas formas de argumentar los derechos sobre los usos del agua, resaltaremos solamente aquella legislación que emanó del estado de Oaxaca y que refleja los diversos procesos, tendencias políticas y administrativas que comenzaban a imperar en la entidad y en el país. Téngase en mente que la legislación estatal, en muchas ocasiones, se podía complementar con la legislación federal, o, en su defecto, también podían tener ciertas confrontaciones.

A la par, también pretendemos realizar una contribución a los estudios históricos en torno al agua en México, muchos de los cuáles dialogan con la jurisprudencia federal con el fin de presentar los momentos de centralización, federalización y nacionalización de los afluentes, y cómo respondieron los llamados "usuarios". ${ }^{4}$ Sin embargo, deseamos llamar la atención a la necesidad de abundar y profundizar en los 
estudios de los recursos naturales para Oaxaca, y, más específicamente, sobre los Valles Centrales, donde la historiografía es escasa. ${ }^{5}$ Llaman la atención los exiguos análisis no solo para el siglo XIX y la primera mitad del siglo XX (Sánchez G., 2015, pp. 235-258 y 2013, pp. 90-92; Topete 2015; 2017, pp. 391-423 y 2018, pp. 136-162; Lira, 2008, pp. 107-109 y pp. 170-171), sino incluso para el periodo colonial (Fernández, Enfield y O'Hara, 2004), aun con su importancia para la consolidación y desarrollo de las sociedades rurales.

Por otra parte, existen esfuerzos historiográficos en Oaxaca que nos llaman la atención sobre los reglamentos de aguadores, la salud, y el sistema de alcantarillado de la ciudad de Oaxaca (Mendoza, 2016b, pp. 325-364; Sánchez R., 2017, pp. 29-31; Topete, 2018, pp. 136-162). A la vez, se ha observado de manera paralela el papel de los ayuntamientos como otorgadores de derechos y usos del agua; se han realizado estudios de los contratos con diversas empresas, como la de los textiles y las generadoras de energía eléctrica (Arellanes, 2008, pp. 131-168; Sánchez G., 2012, pp. 215-242), pero no hemos elaborado una visión de conjunto sobre los Valles Centrales.

En torno al análisis de la legislación en Oaxaca, resalta los esfuerzos por observar las implicaciones de la Ley de aguas de 1905, en términos de las concesiones que implicaría, a decir de algunos autores, una doble centralización, es decir, a la federal se le agregaría la estatal (Sánchez G., 2012, pp. 215-238; Topete, 2017, pp. 391-423). Sin embargo, habría que adelantar que, básicamente las leyes que se publicaron previamente -no todas versan sobre el agua de manera exclusiva- contenían artículos sobre las aguas municipales o comunes, y estaban sustentadas en formas de derecho administrativo; esto es, son legislaciones que llevaban a la gestión y administración de "manera correcta" de las aguas tanto privadas como públicas (Pérez de Yarto, 1894; Toxqui-Furlong, 2018, pp. 101-107).

En términos del escenario, estamos centrándonos en lo que se ha llamado el "Acuífero Valles Centrales”, el que se localiza en la porción centro del estado de Oaxaca (véase figura 1 al final del artículo) y está constituido por tres valles: Etla, Tlacolula y Zimatlán, que convergen en el área donde se ubica la Ciudad de Oaxaca. Comprenden una extensión de $5,940 \mathrm{~km} 2$, de los cuales aproximadamente $1,130 \mathrm{~km} 2$ conforman la zona de extracción de agua subterránea (Comisión, 2018, p. 4).

Los dos ríos más importantes de los Valles Centrales -que forman tres brazos en el centro del estado de Oaxaca-, el Atoyac y el Salado, transcurren por un suelo con grandes desniveles, lo que, de hecho, propició la formación de cavernas que hacían "desaparecer" al último río mencionado. El río Atoyac nace cerca de San Sebastián Sedas, en el valle-ex-distrito de Etla, a elevaciones del orden de los 2,000 metros sobre el nivel del mar (m. s. n. m). En su primer tramo toma una dirección general hacia el sureste hasta la Ciudad de Oaxaca, donde ingresa a la zona geohidrológica de Zimatlán y a la altura de San Agustín de las Juntas (ex distrito del Centro) recibe por la margen izquierda las aguas del río Salado, que es uno de sus principales afluentes (Comisión, 2018, p. 11; véase figura 1 al final del artículo). El río Salado tiene una trayectoria que inicia al oeste del municipio de San Pablo Villa de Mitla (valle y ex distrito de Tlacolula). En términos políticos, a partir de la división política de 1858, los Valles Centrales contenían a los distritos de Etla, Tlacolula, Centro, Ejutla, Ocotlán y Zimatlán, los cuales perduraron durante gran parte de la segunda mitad del siglo XIX y al menos las primeras dos décadas del siglo XX.

Por otra parte, hay que considerar que la porosidad del suelo impedía grandes obras de infraestructura para la captación y conservación del agua en tiempos de estiaje, por lo que se optaba por "presas provisionales" (tierra, piedras y ramaje), que con la crecida de las avenidas desaparecían. Por ejemplo, en 1928 se comentaba que en Santa María Atzompa (distrito del Centro) que la "práctica se ha seguido desde inmemorial tiempo, [la que] está de acuerdo con las disposiciones del Estado cuando era su jurisdicción”, y seguía siendo utilizado por los pueblos que tenían ejidos en las primeras dos décadas del siglo XX. ${ }^{6} \mathrm{~A}$ la par, ya sea cavando pozos o en los terrenos a las orillas de los ríos, se practicaba el riego con cántaros. Es así que, además de la temporada de estiaje, los suelos porosos -se consideraban "arenosos" los bordes del río- y sus grandes irregularidades, sumados a un importante número de actores sociales (véase figura 1 al final de este artículo y Tabla 1) que requerían agua (pueblos, haciendas, ranchos, molinos) y al accionar de los intermediarios son 
elementos importantes que se deben considerar a la hora de analizar el siglo XIX y las primeras décadas del $\mathrm{XX}$-observándolo como un proceso de transición más no de rupturas-. Además, deben tenerse en cuenta las formas en que los distintos actores sociales resolvieron o se adecuaron a estas características geográficas de los Valles Centrales, para hacer uso de los recursos hídricos.

\section{ESTRUCTURAS AGRARIAS}

En los Valles Centrales existieron haciendas, ranchos, rancherías, pueblos indígenas y mixtos, así como trapiches y molinos (véase Tabla 1 y figura 1), tanto en el periodo colonial como en el republicano y revolucionario. Localidades y unidades productivas que contenían una diversidad de población tanto en términos étnicos como socioeconómicos. Casi todas las haciendas de los distritos de Etla, del Centro, de Ocotlán y Zimatlán se encontraban compartiendo el río Atoyac o sus afluentes. Algunas eran cruzadas en sus terrenos por ríos perennes, lo que les permitía defender las servidumbres e incluso traspasarlas cuando se vendía la propiedad. En el caso del distrito de Tlacolula, la mayoría de los pueblos y haciendas utilizaban el río Salado, fuera para riego, para realizar entarquinamiento (Sánchez R., 2018), marcar límites o saciar las gargantas de los humanos y animales (véase la Figura 1 al final del artículo). Y solo en el caso de las haciendas de Alférez, Xaagá, Tanive, ubicadas en el Distrito de Tlacolula, hemos encontrado datos y vestigios físicos de presas de mampostería, las cuales captaban el agua de los arroyos que bajaba de las sierras. La utilización de terrenos de riego no solo era para el maíz o trigo, sino para otros cultivos. Por ejemplo, en 1897, se informaba que, en los distritos del Centro, Ejutla y Etla la caña de azúcar era de riego (Estado, 1897), por lo que los afluentes principales y secundarios eran de suma importancia no solamente para el cultivo, sino también para mover las maquinarias de los ingenios, como en el caso de las haciendas Concepción y Guadalupe (ambas en el valle y distrito de Etla). ${ }^{7}$

La densidad de actores sociales que se registró en el periodo colonial no varió en demasía a la que encontramos en el siglo XIX y principios del siglo XX (Taylor, 1998, pp. 153-156 y pp. 217-224; Gerhard, 1986, pp. 48-53, 90-93, 147-148, 314-319; Tanck de Estrada, 2005, p. 140 y p. 147; Chassen-López, 2004, pp. 105-121). Podemos apreciar en la Tabla 1 cómo los pueblos eran numéricamente superiores a las haciendas y ranchos, lo que no evitaba una fuerte competencia por los recursos entre los diversos actores sociales, ya fuera en términos colectivos o individuales. Por otro lado, varias haciendas no sobrepasaban las 30 hectáreas (ha), como en el caso de Aguayo (municipalidad de Xoxocotlán, Distrito del Centro); ${ }^{8}$ algunas otras pasaban de las ocho mil ha, como Matagallinas (Distrito de Zimatlán), Poblete (Distrito de Ejutla) contaba con un poco más de 15 mil; incluso hubo haciendas más grandes como la de El Vergel con más de 30 mil ha, o la Compañía (ambas en el Distrito de Ejutla) con casi 51 mil ha (Chassen-López, 2004, pp. 105-121).

Ahora bien, una reestructuración agraria y territorial muy importante se dio con el proceso de restitución o dotación de ejidos, durante el periodo posterior a la revolución mexicana de 1910. Al mismo tiempo, el reparto agrario propició una lenta desaparición de haciendas, así como el surgimiento de ejidos y otras localidades que exigían tener una categoría política como "municipio". De esta manera se agregaba un nuevo actor (el ejido) que competía por los recursos, con el cual también se dieron tensiones en una misma localidad, que se manifestaron más en identidades políticas que étnicas. Así tenemos la queja del presidente municipal de Santa María Atzompa (distrito del Centro) en febrero de 1927 sobre los “encabezados" del partido agrario de la localidad, quienes impedían el uso del agua, por medio de "una zanja (...) con la que mudaron la corriente del río y quitar el agua que sirve para los riegos y servicios de todo el pueblo". 9

En suma, la importancia de los Valles Centrales radica en que fueron y son espacios socioproductivos, generadores de recursos, donde el agua adquiere el carácter de bien al que todos buscan tener acceso, a pesar de las tensiones sociales. Los habitantes de los pueblos que accedían al vital líquido -es claro que no todos 
los vecinos eran usuarios del agua-, ya fuera porque sus tierras estaban cerca de las riberas del río Atoyac o del río Salado -si consideramos los afluentes que los nutrían - recibían las concesiones de los ayuntamientos, fuera con base en las leyes estatales o porque así lo marcaban los usos y costumbres. Las instancias políticasadministrativas vendían y otorgaban derechos de agua a los hacendados, empresas e hidroeléctricas -como en el caso de San Agustín y las fábricas San José y Vista Hermosa, ubicadas en el valle-distrito de Etla-, fuera para las mejoras de los pueblos, o sencillamente para cubrir déficits municipales, como en el caso del ayuntamiento de San Juan del Estado (valle y distrito de Etla), que en 1928 decía ser propietario del río San Juan y que lo había aprovechado desde "tiempo inmemorial". Este derecho lo asumía con base en el reconocimiento que los ribereños le daban a través de los contratos para el uso de las aguas. ${ }^{10}$ De esta manera el ayuntamiento se presentó como un actor de primer orden en los procesos de autorización, venta y concesión de derechos del agua. Esto es lo que se pretende eliminar por las instancias federales a fines del siglo XIX y bajo los gobiernos posrevolucionarios (Aboites, 1998; Aboites y Estrada, 2004; Sánchez R. y Sandré, 2011, pp. 34-52). A fines de 1900 se realizó un censo por distritos y a su vez por municipalidades y agencias, categoría de la localidad y número de población, lo que nos permite abundar sobre el uso del agua por algunas propiedades.

TABLA 1

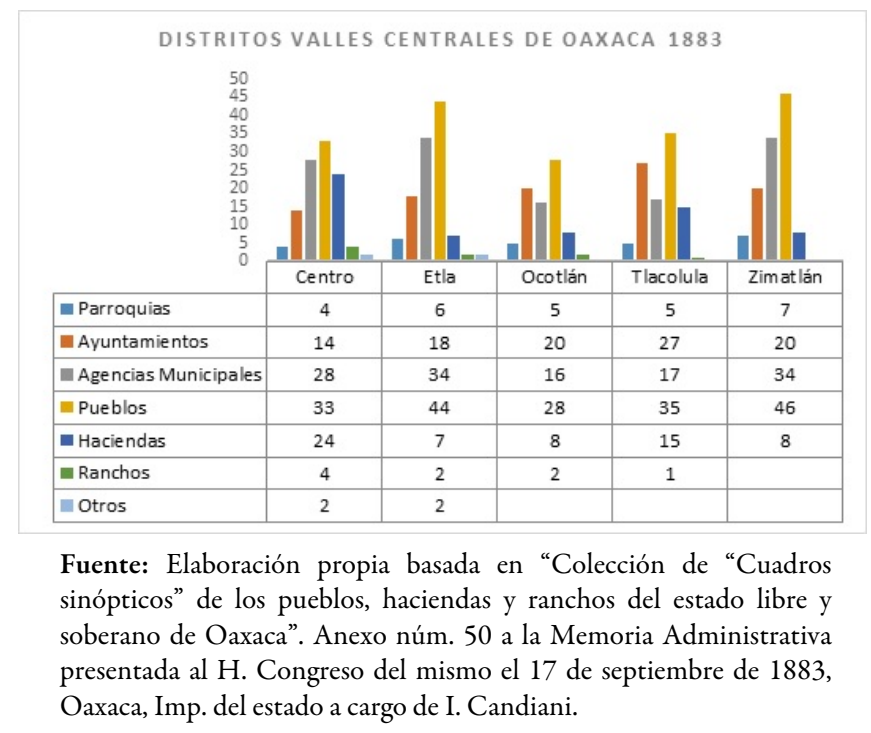

Los datos que arroja el censo por los distritos correspondientes a los Valles Centrales nos muestran que, en el caso del Centro, las propiedades privadas del distrito tenían un acceso al río Atoyac o al Jalatlaco -que cruzaba la ciudad de Oaxaca-, a su vez contaban con pozos (Sangre de Cristo, Cinco Señores, San José) o con norias (La Concepción). La hacienda de El Rosario estimó en 1919 sus 51 hectáreas de riego en 600 pesos cada una; mientras que sus 63 ha de medio riego fueron valoradas en 400 pesos cada una y se mencionaba que tomaba agua del río Grande. ${ }^{11}$ Otras haciendas aprovechaban el agua que provenía de los acueductos de Hueyapan y San Felipe, como San Luis y Aguilera, y que nutrían de agua potable a la ciudad de Oaxaca. En el caso de los pueblos, la mayoría utilizaba el Atoyac o tenían arroyos que cruzaban sus terrenos y que desembocaban en dicho río. Para el distrito de Tlacolula las haciendas y varios pueblos utilizaban agua del río Salado (Secretaría de Fomento, 1906).

\section{OAXACA Y SU LEGISLACIÓN SOBRE AGUAS}

En la segunda mitad del siglo XIX se buscó, de manera constante, reglamentar, organizar y poner en "orden" a los habitantes no solo a nivel estatal sino también nacional (Sánchez R. y Sandré, 2011, pp. 32-82), lo que se fue reflejando a través de las leyes nacionales en torno al agua en las postrimerías del siglo antepasado, 
como con el proceso de dotación ejidal, que comenzó en los Valles Centrales, a mediados de la década de 1910. El surgimiento de leyes que llevaban en su interior formas de derecho administrativo se dio en diversos momentos históricos. Entre las formas jurídicas coloniales (léase españolas) y la hibridación de las normas norteamericanas, francesas y españolas, lo único que quedaba claro en la legislación decimonónica era la importancia que tenía diferenciar entre aguas públicas y privadas, lo que implicaba una transición entre el derecho internacional, el constitucional, el administrativo y el civil en el México de la segunda mitad del siglo XIX y los primeros años del siglo XX (Pérez de Yarto, 1894).

Debemos de considerar que, con la primera ley federal sobre el agua del 5 de junio de 1888, se comenzaba la intervención directa del gobierno federal en el control, manejo y administración del agua. Bajo esta ley se pretendía recuperar el dominio eminente que ostentó la Corona española y se daba un banderazo de salida a la centralización político-administrativa en torno a la gestión del agua (Sánchez R. y Sandré, 2011, p. 52). El proceso alcanza un clímax con la expedición de la Ley de Aguas de 1910 -que instaba a los usuarios a reconocer a la autoridad del gobierno federal respecto de las aguas federales mediante la obligación, tanto para viejos como para nuevos usuarios, de tramitar ante la Secretaría de Fomento las concesiones o confirmación de derechos-, pero sobre todo en el artículo 27 de la Constitución de 1917, por el que la nación retomaría la propiedad de las aguas, cediendo el dominio útil de las mismas a concesionarios privados o "colectivos", lo que llevó a un mayor "control" del recurso hídrico por la administración federal (Nuñez, 2009, p. 141). El camino federal produjo conflictos con los gobiernos municipales y estatales, quienes recurrieron a diversos argumentos, como la soberanía, para evitar una injerencia total en la administración del bien. Aquí debemos de mencionar que los manantiales, aguas torrenciales, aguas subterráneas, no se incluían en el rubro de aguas nacionales del artículo 27 constitucional (Reich, 2017, pp. 119-157).

¿Qué tanto se aplicaba en las realidades rurales la legislación? La legislación no solamente trataba de impactar a quienes era dirigida, sino de qué manera y cómo las utilizaban quienes conocían las leyes, sea para defender, actuar o sencillamente evadirlas. Las variantes se podían exhibir en la negociación y acuerdos, pero también en los argumentos que presentaban las partes en conflicto e incluso en la conveniencia o no de utilizar otras leyes, decretos o circulares que fueran benéficas para alguno de los contrincantes. Sin duda, se puede pensar que pocas leyes eran conocidas por los actores sociales en su cotidianidad, aun cuando algunas respondían a ella. ${ }^{12}$ Tendríamos que considerar que son los intermediarios -síndicos, tinterillos, abogados, apoderados, "patrones" - quienes manifestaban parte del sentir de quienes representaban, elaborando textos que expresaban lo que deseaban escuchar aquellos a quienes iban dirigidos, pero que, a su vez, también contaban con elementos de quienes impulsaban el litigio o la duda sobre alguna legislación.

Los estudios que han optado por la metodología de Rosa Congost (2007) ponen sobre la mesa una amplia gama de formas y maneras de derechos sobre los bienes, los cuales en muchos casos se sobreponen (p. e., Barcos, Lanteri y Merino (dirs.), 2017). Pensamos en el tiempo inmemorial, usos y costumbres y en distintos tipos de derechos sobrepuestos, conceptos e ideas que aún se nos escurren en términos conceptuales. Por ejemplo, en 1924, en un interrogatorio para comprobar el pago del agua de la hacienda Catano, al ayuntamiento de San Juan del Estado, ambos en el distrito de Etla, se preguntó a los testigos qué entendían por "tiempo inmemorial", a lo que respondieron: "Una época anterior de la que no se puede precisar el número de años" y "lo de muchos años sin que pueda precisarse la fecha". ${ }^{13}$ Sin embargo, estas dos ideas implicaban definir derechos de uso por parte de los actores sociales.

Comenzaremos con el Código Civil de Oaxaca, que se promulgó entre 1827 y 1829. En 1827, se publicaron las disposiciones preliminares y su libro primero; en 1828, el libro segundo, y 1829 el último libro (Código Civil, 2010), que, si bien estuvo vigente hasta 1837, muestra la transición entre el periodo colonial y el propiamente republicano, tomando algunas variantes de los códigos europeos, principalmente el napoleónico (Arrioja, 2010, pp. 33-37). Lo que deseamos resaltar es que, aun con su abolición, en la tercera década del siglo XIX algunos de sus elementos pervivieron en la mente de los legisladores e intermediarios oaxaqueños, al menos en lo relacionado al agua, a la tierra y a lo que implicaba la propiedad en sí. Estos elementos, con los 
matices correspondientes, se vieron reflejados en las leyes, decretos y reglamentos de la segunda mitad del siglo XIX. Asimismo, hay que considerar que fue uno de los primeros códigos civiles en el país, lo que no implica que a mediados del siglo XIX aparecieran otros en calidad de proyectos, como en Jalisco y Guanajuato. Hasta que en 1870 se expidió un código civil que consideraba al distrito federal y territorios, pero que fue asumido por las diversas entidades del país y que fue nuevamente modificado en 1884 a nivel federal.

De este modo, en el Libro Segundo del Código civil, en su Título I, artículo 411, se determinaba que los "ríos navegables o flotables" que no fueran propiedad privada pertenecían al estado de Oaxaca. Un elemento esencial tanto en el derecho hispano como en el posterior derecho republicano era lo que implicaban las servidumbres, por lo que en el Título IV y de los artículos 507 al 515 se definieron. Lo importante de esta serie de artículos es que va delimitando entre las aguas privadas y las públicas, incluso en el 515 se menciona que los pleitos se definirán a partir de reglamentos particulares sobre el "curso y uso de las aguas" (Código Civil, 2010), los cuales al parecer nunca se realizaron.

La segunda mitad del siglo XIX mexicano fue definida por las luchas de poder, invasiones extranjeras, intentos de impulsar reformas que afectaban la corporatividad de la Iglesia, los ayuntamientos y los pueblos indígenas. Fue un periodo influido por las ideas liberales del individuo, de la propiedad perfecta, del derecho administrativo, la centralización y federalización de los recursos (Aboites, 1998; Toxqui-Furlong, 2018), así como por el libre comercio sustentado en productos de alto valor comercial, las mejoras en la infraestructura de comunicación y la búsqueda del equilibrio de la inversión extranjera. En síntesis, fue el siglo del liberalismo económico.

Oaxaca fue prolífico en leyes y decretos en torno a lo que implicaban los bienes comunes. En muchos casos se partía de lo que marcaba la ley de desamortización, del 25 de junio de 1856, por lo que los juristas decimonónicos impulsaron formas de derecho administrativo. Por otra parte, lo que debemos de resaltar en el caso de Oaxaca es que, pese a que se buscara que el ayuntamiento dejara de controlar tierras -lo que implicaba en sí la desamortización civil-, se le dejó el control y manejo de las aguas. Se le otorgaba de esta manera una fuente importante de ingresos por el líquido, así como una nueva capacidad para dirimir tensiones sociales, como en el caso del municipio de San Guelache (valle y distrito de Etla), en donde, en 1912, se cobraba según la costumbre y el tiempo que se ocupaba el agua. También tenemos el caso del ayuntamiento de Tlacolula (distrito del mismo nombre), que en 1903 le cobraba a la hacienda Alférez impuestos por la utilización de una toma provisional de "estacado y madera". ${ }^{14}$

La preocupación de los hombres públicos oaxaqueños del siglo XIX se centró en emitir disposiciones que llevarían al fraccionamiento y repartición de los bienes comunes (tierra y bosques), aun cuando pareciese que en parte legitimaban ya un proceso de individualización que ya se daba en los pueblos indígenas. En términos federales no hubo una ley clara que marcara la posible división de las "aguas comunes", pero sí decretos sobre los lagos, lagunas y aquellas aguas consideradas como "estancadas". Aun con las leyes federales y estatales en contra de las corporaciones civiles y eclesiásticas desde mediados del siglo XIX, en 1862 se publicaría un reglamento en Oaxaca relacionado a la división de los terrenos comunes, pero que en su artículo 34 consideraba que los ayuntamientos podían "rentar" o traspasar derechos de uso sobre sus afluentes a los vecinos de las localidades, con la facultad de exigir pagos sobre la utilización de las aguas a los diversos usuarios (Hernández, 1902, III, pp. 361-370). De esta manera, la ley daba el marco y argumento jurídico en el cual muchas de las solicitudes y problemáticas sobre las aguas se fueron presentando, hasta que, en años posteriores, se implementó una ley sobre las servidumbres.

El 18 de noviembre de 1873 se publicó una ley específica sobre las servidumbres de agua, la que diferenciaba entre aguas que pertenecían al gobierno estatal y las que estaban en manos de particulares, siguiendo la vertiente del código civil de los años veinte. Los diversos artículos de esta ley, en sí, precisaban la manera en que podían utilizarse las servidumbres, así como las formas del traslado de las aguas de predio en predio, con las indemnizaciones correspondientes a los propietarios de los mismos (Hernández, 1902, VI, pp. 383-388). En síntesis, se refería a que los municipios podían tener el derecho de poseer en común las aguas que hasta 
ese momento habían poseído -contraviniendo la ley federal de 1856 sobre bienes comunales-, así como la capacidad de arrendar los derrames después de haber sido utilizados por los vecinos. De esta manera, se ponía al ayuntamiento como la máxima autoridad local en la administración y gestión del agua.

El 26 de junio de 1890 salió publicado el "Reglamento para la adjudicación de terrenos comunales", que en su artículo 39 consideraba, nuevamente, que el uso de las "aguas comunales" se reglamentaría por los municipios. En estos "reglamentos municipales" se cuidaría, sobretodo, el reparto de las aguas, y las decisiones debían ser aprobadas por el gobierno del estado. ${ }^{15}$ En este momento se consideraba que las aguas eran de los pueblos y de los vecinos que los habitaban. Sin embargo, se puede entrever que quienes realmente manejaban -administraban- el recurso hídrico y lo arrendaban eran los ayuntamientos, que celebraban contratos con diversos usuarios, como haciendas, ranchos, vecinos, pueblos y fábricas. Por ejemplo, en abril de 1888, el ayuntamiento de San Juan Guelache (valle y distrito de Etla) y Ramón Cajiga refrendaron el arrendamiento de una "tanda de agua para riego", que disfrutaba la hacienda de Dolores por 120 pesos, el doble que el primer arrendamiento realizado en $1863 .^{16}$

Debido a lo que marcaban las leyes y los reglamentos de 1862 y 1890, el agua fue un bien común importante, no solamente para esgrimir derechos, sino también como factor de negociación, al menos para los ayuntamientos, los cuales quizá le daban más valor que a la propia tierra.

A comienzos del siglo XX se dio una nueva ley sobre las aguas; se trata de la Ley sobre el uso y aprovechamiento de aguas del Estado de Oaxaca, promulgada el $1^{\circ}$ de febrero de 1905 . Uno de los objetivos principales de esta ley era regularizar el uso y el aprovechamiento de las aguas públicas del estado, dado que hasta esa fecha y en la práctica cotidiana:

(...) el uso y aprovechamiento de estas no ha tenido regla fija a que sujetarse, pues unos las utilizan sin autorización alguna considerándolas como bienes cuyo uso es común a todos estimándose con el derecho de primer ocupante, otros ocurren al ayuntamiento de los pueblos proponiendo contratos de arrendamiento de las aguas mediante pensiones reducidas y en menor número hacen ante el gobierno solicitudes formales de concesión (Ley, 1905).

En la ley de aguas del estado de Oaxaca de 1905, que incluso se asemejaba a la "Ley sobre el uso y aprovechamiento de aguas del Estado de Michoacán" de 1906, en el sentido de "administrar" las aguas de la entidad y de otorgar las concesiones de las consideradas aguas del estado (Sánchez R. y Sandré, 2011, pp. 286-314), observamos que se insistía en que eran los ayuntamientos o las agencias municipales quienes las podían administrar (artículo 36). Esto demuestra que se fueron reconociendo los derechos de los pueblos en torno al agua pública, aun cuando la ley federal de 1888 pretendía la federalización de los recursos, y postulaba que el gobierno federal era el único que podría otorgar las concesiones sobre el recurso hídrico (Exposición, 1904; Ley 1905). Lo que no consideraron los diputados oaxaqueños -a pesar de buscar posibles contradicciones con la ley del 5 de junio de 1888 sobre aguas de México-, quienes además siguieron casi a pies juntillas varios de los artículos de la ley española de 1879 (Ley de Aguas, 1879) ${ }^{17}$, es que ambas reconocían para la aplicación de las aguas públicas, en sus aprovechamientos especiales, cierta preferencia o prelación de lugar, y el abastecimiento de las poblaciones. ${ }^{18}$

En términos generales, la gestión del agua en Oaxaca era una cuestión de intereses y relaciones sociales a nivel local, en la que coexistían varias formas de acceder al líquido, normadas con base en usos y costumbres que se manifestaron en los diversos reglamentos estatales y en la Ley de 1905. Quizá nada diferente al resto del país, pero se les otorgó a los ayuntamientos una capacidad de negociaciones y de concesión de derechos importante, que le permitió a esta instancia política-administrativa utilizar el agua como elemento de poder y negociación, por lo que las concesiones fueron una forma de regular la explotación de los bienes sujetos al "uso común" (Nuñez, 2009, pp. 140-141).

Un factor importante para que el gobierno estatal quisiera regularizar el uso de las aguas fue que, al generarse una mayor demanda de líquido por las diversas industrias, las solicitudes de concesiones del líquido fueron en aumento. ${ }^{19}$ La Ley de aguas de 1905 posibilitó que el gobierno pudiera tener un mayor manejo 
sobre dichas concesiones - aunque continuaba delegando a los municipios la facultad de administrar y hacer convenios sobre las aguas que estuvieran dentro de su jurisdicción- lo cual se siguió usando de manera constante y dio lugar a fuertes tensiones y se dieron relaciones manejadas a través del poder.

Un año después de la expedición de la ley, el gobernador Pimentel mencionaba la presentación de 54 expedientes de solicitudes de concesiones, las que, si bien habían enfrentado oposición, no se habían dirimido en los juzgados sino en las juntas de avenencia, por lo que consideraba que había respondido a lo que se pretendía, es decir, "dar a los mercedados títulos firmes y legítimos para el aprovechamiento y uso de las aguas públicas” (Mensaje, 1906, pp. 39-40). Una de las primeras haciendas que refrendó sus títulos sobre las aguas fue la que albergaba los Molinos del Lazo (en el distrito de Etla). ${ }^{20}$

Con base en la ley de 1905 sobre aguas, algunos ayuntamientos prohibían el uso del líquido a los vecinos, como en el caso de Teotitlán del Valle (Distrito de Tlacolula) en 1906, o el de San Juan Guelache (valle y distrito de Etla), que, en el año de 1911 definía los impuestos en torno al uso del agua con base en la "costumbre", argumentando que tenía la administración del agua del río Grande que nacía en terrenos de “aprovechamiento comunal". ${ }^{21}$ Tanto la ley estatal de 1905 como la federal de 1910 sirvieron para que los ayuntamientos reclamaran sus derechos frente a instancias gubernamentales. Un caso que nos es útil para mostrar esta situación, se presentó en el año de 1925, entre el municipio de San Juan del Estado (Distrito de Etla), y la Secretaría de Agricultura y Fomento (SAyF) -instancia federal-, la que a consideración de las autoridades municipales había violado la soberanía del estado al desconocer los derechos que sobre el río de Santa Lucía tenía el municipio. Éste poseía una composición de 1719, que era considerada como título legítimo sobre las aguas. ${ }^{22}$ Ejemplo que muestra que la interpretación realizada por Luis Aboites y Valeria Estrada (2004) es certera, en el sentido de los problemas de "jurisdicciones" entre las instancias federales y las locales, ya que no solamente les quitaban la capacidad de cobrar sobre el recurso, sino también de no otorgar concesiones ni tampoco dirimir conflictos, por lo que supuestamente perderían injerencia en la vida local y regional. Otro ejemplo, es el del río Salado, ubicado en el valle y distrito de Tlacolula. En este caso observamos cómo el agua se presentó como un elemento de poder y negociación entre el ayuntamiento, la Comisión de Aguas Local (CAL) -conformada por los usuarios del río-, los medieros, los ejidatarios y los propietarios privados. La tensión social fue así: a principios de 1930, los vecinos de Tlacolula se quejaban de que el presidente municipal les negaba el agua para sus siembras; sin embargo, él argumentaba que la encargada de distribuir el agua era la CAL, por lo que esta se enfrentó con el presidente municipal en mutuas acusaciones en torno a la decisión sobre a quién le correspondía el líquido; para 1933, después de muchos dimes y diretes entre las autoridades municipales y la CAL, así como entre los medieros y ejidatarios, se decidió que se realizaría un reglamento de aguas por parte de la Comisión Local Agraria para ver cómo los 156 propietarios, los 62 ejidatarios y los 16 medieros obtendrían el acceso al agua. ${ }^{23}$

La problemática en torno al río Salado había tenido otras características y otros actores sociales unos años antes. El conflicto se centraba en por dónde pasaba el agua, quiénes aprovechaban las servidumbres, los derrames, y sobre el papel que fue asumiendo el ayuntamiento como "propietario" de los derechos del líquido. El inicio documentado del conflicto data de principios de 1896, cuando los dueños de la hacienda de El Alférez ${ }^{24}$ se quejaron de que el municipio estaba construyendo obras que "interceptaban" el líquido que trasladaba el río Salado. Por su parte, el ayuntamiento argumentó que, con base en el Reglamento del 25 de marzo de 1862, tenía el derecho de “poseer en común, así como arrendar los derrames”. Esta declaración deja entrever que, muy probablemente, se pretendía arrendar el cauce del río. ${ }^{25}$

Sin embargo, unos meses antes de noviembre de 1895 (exactamente el 27 de noviembre), el secretario del gobierno estatal ordenaba al jefe político de Tlacolula que hiciera efectiva una multa que se le había impuesto a ese ayuntamiento, y que informara sobre la suspensión de los trabajos del dique del río Salado, con el fin de evitar "perjuicios" en las sementeras de la hacienda del Alférez por habérsele interceptado el agua. Un año más adelante, en una comunicación fechada el 26 de noviembre de 1896, en relación con la multa y al uso 
de las aguas del río Salado, el presidente municipal de Tlacolula le argumentó al gobernador de Oaxaca que ese pueblo: “...desde remotos tiempos que lleva de hacer uso de aguas del Río Salado, la coge en sus propias tierras sin tocar para nada las aguas y sin que ninguno de los anteriores dueños del Alférez haya pretendido prohibirle el goce de ese derecho". ${ }^{26}$

Veintiún años después (1917), el gobierno de Oaxaca volvía o continuaba ordenando al ayuntamiento destruir el dique que impedía que las aguas llegaran a la hacienda, por lo que el ayuntamiento se amparó, apelando a que el río era de propiedad nacional, por lo que le correspondía a la Secretaría de Agricultura y Fomento (SAy F) “dictar sobre sus aguas". Incluso, el presidente de Tlacolula se amparó en el artículo 27 de la Constitución de 1917, al mencionar que los ríos eran de dominio de la nación. Ahora, a diferencia de lo que argumentó San Juan del Estado (Distrito de Etla), a finales del siglo XIX, en torno a la soberanía del estado frente a la federación, el ayuntamiento se enfrentó al gobierno estatal quitándole jurisdicción con el argumento de que el río era de propiedad nacional, por lo que correspondía al gobierno federal definir las concesiones. Sin embargo, no fue hasta el 2 de marzo de 1921 que el río se declaró propiedad nacional. En este sentido, como lo han observado Luis Aboites y Valeria Estrada (2004, pp. 28-29) para otras partes de México, los ayuntamientos buscaron "afanosamente la intervención de las autoridades federales para aclarar derechos y dirimir conflictos".

Desde esta perspectiva, y considerando el proceso iniciado con la revolución de 1910, así como lo considerado en el artículo 27 constitucional de 1917, podemos observar y reiterar que el papel de la Nación es central, no solamente para definir quién otorga los derechos sobre el agua a través de las concesiones, sino quién es directamente el dueño de esos recursos.

El nuevo marco jurídico permitió al gobierno federal expedir leyes que regularan las aguas nacionales destinadas a la irrigación y a la producción de energía eléctrica. Así, el 6 de julio de 1917, el presidente Venustiano Carranza expidió un decreto en el que establecía una renta federal sobre el uso y el aprovechamiento de las aguas públicas sujetas al dominio de la federación. Los concesionarios de las aguas federales se negaron a pagar el nuevo impuesto y argumentaron para ello que todavía sufrían el ataque de los grupos revolucionarios (Castañeda, Escobar O. y Andrade, 2005). Casi una década después, en 1926, el presidente Plutarco Elías Calles decretó la Ley sobre Irrigación con aguas federales, que declaraba de utilidad pública "la irrigación de las propiedades agrícolas privadas", siempre y cuando usaran aguas de jurisdicción federal. Para construir las obras de irrigación en la república mexicana fue necesario formar un órgano administrativo: la Comisión Nacional de Irrigación, que dependería directamente de la SAyF (Lanz, 1982, II, 81).

La paulatina centralización que implicaría la administración de las aguas por parte del gobierno mexicano desarticuló los mercados locales de aguas, en los que los pueblos y particulares vendían o intercambiaban este recurso; incluso podríamos aseverar que trastocó los sistemas de riego locales. Así, en 1930, la SAyF recibió informes en los que se asentaba que algunos pueblos de Etla, Ocotlán y Zimatlán continuaban con la práctica de vender el agua, pese a la prohibición de hacerlo, lo que a su vez nos muestra que el proceso de "centralización" aun encontraba muchas dificultades para su aterrizaje en el mundo rural.

\section{EN BÚSQUEDA DE MEJORAR LA AGRICULTURA Y LA DISTRIBUCIÓN DEL AGUA EN EL SIGLO XX}

Los usuarios se enfrentaban a diferentes situaciones, sobre todo cuando buscaban hacer uso del agua, principalmente por no saber a quién o a quiénes solicitar las concesiones de agua. Los propietarios privados se amparaban en las concesiones otorgadas bajo la ley estatal de 1905, y los pueblos y aquellos que habían recibido dotación de tierras se amparaban en que el gobierno les había otorgado las aguas con base en las leyes posrevolucionarias. Por otro lado, las leyes, basándose en sus características, en el sentido de desembocar en el mar, ser de carácter permanente y servir de límites entre dos entidades de la Federación, declararon a los ríos como propiedad nacional. Por ejemplo, el río Salado se declaró como corriente nacional el 2 de marzo de 1921 
y el Atoyac el 23 de enero de 1920. La declaración de propiedad nacional marcaría un cambio en la historia de los usos del agua en México, dado que convertía al gobierno federal en el único sujeto con capacidad para otorgar las concesiones sobre las corrientes de agua.

De este modo, las características de los afluentes y ríos explicarían las formas de negociación y conflicto que se presentaron a lo largo del siglo XIX y las primeras décadas del siglo XX. Es así que, además del factor geográfico, la porosidad del suelo, y los usos y costumbres, el elemento central para nuestro análisis de lo que implicó el siglo XX es el papel que ejercieron los funcionarios públicos en torno al agua, como lo fueron: los jefes políticos, los gobernadores, las Comisiones Locales y la Nacional Agraria, los ingenieros, el procurador de Aguas de la Secretaría de Agricultura y Fomento, y el procurador de Pueblos. Todo ello, aunado al tipo de documentos consultados para este trabajo, hace que el papel de las instancias gubernamentales aparezca en primer plano. Al mismo tiempo, y como mencionamos en la introducción, se puede observar una aparente relación vertical entre el gobierno y los diversos usuarios; y decimos aparente porque a lo largo de la misma se ven intermediarios e intereses que se entrelazan con el proceso a lo largo de los cientos de fojas estudiadas.

A nivel nacional, y con los sucesos revolucionarios, durante las primeras décadas del siglo XX, y sobre todo después de 1910, hubo un planteamiento incesante en torno a la irrigación para la agricultura. Uno de los argumentos era que la irrigación aumentaría la producción agrícola, por lo que los gobiernos posrevolucionarios buscaron impulsarla con la idea de que, a la par de repartir la tierra, también se repartiera el agua bajo la idea de la "justicia social". Pero esto fue idílico, ya que, aun cuando muchas de las dotaciones agrarias consideraban las tierras de riego, el proceso de accesión (dotación de aguas) no fue a la par de la dotación de tierras. En este sentido, Oaxaca no fue la excepción. Incluso hubo habitantes de pueblos que exigieron que se les reconociera la "propiedad" del río que cruzaba sus tierras, lo que mostraba las dudas y el desconocimiento sobre lo que implicaban en ese momento las aguas públicas, las privadas y las que se asumían como propiedad de la nación.

Sin embargo, lo que nos va mostrando la documentación es que las haciendas de los distritos de Etla, Tlacolula y Ocotlán defendían su "propiedad" y las concesiones sobre los ríos, incluso oponiéndose a que fuera dotada el agua. Por esta razón, en mayo de 1923 la Dirección Federal de Aguas de la SAyF decidió nombrar un procurador de Aguas, para que, con base en las resoluciones presidenciales de dotación de tierras, se gestionara la distribución del agua entre el pueblo y la finca afectada, incluso que se les otorgara el agua a los terrenos ejidales que incluyeran riego. ${ }^{27}$

Ante el panorama de tensión por la tierra y el agua en México, en los Valles Centrales de Oaxaca, se quiso desarrollar la utilización de las aguas subterráneas a través de presas sumergidas y de galerías filtrantes que pudieran retener el agua y hacerla surgir a la superficie para atender la cuestión de la irrigación a los diversos usuarios.

Es interesante que los argumentos para acceder al agua que se exponen a fines de la década de los 1910 difieren de los que paulatinamente los habitantes de los pueblos y ejidos van presentando a través de la Dirección de Aguas de la SAyF, o a través de las organizaciones campesinas "revolucionarias" que se comienzan a conformar a fines de los 1920 . Viéndolo desde la perspectiva de un actor o intermediario social del momento, el 10 de octubre de 1933 el agrónomo Nabor Ojeda, quien fungía como "Organizador Regional de Ejidos del Estado de Oaxaca”, informaba que los 75 ejidos que conformaban los "distritos” del Centro, Etla, Tlacolula, Ocotlán y Ejutla carecían de dotación de aguas, aun cuando habían realizado las solicitudes pertinentes. Ojeda propuso que se realizara un estudio que definiera un sistema de canales, jagüeyes y presas que permitiera compartir el agua entre los ejidos y algunas de las haciendas. Además, señaló que, con la implementación de esta infraestructura hidráulica, se posibilitaría un sistema de riego más integrador y "equitativo". ${ }^{28}$ Sin embargo, lo que demuestra la carta de Ojeda es que los actores sociales mantenían en sus manos el agua sin notificar a los gobiernos.

Con el fin de cumplir con una parte del "ideal revolucionario" que estaba en relación con la irrigación, y viendo las condiciones geográficas de los Valles Centrales, en junio de 1938 en la Revista de Irrigación 
en México se publicó un artículo del ingeniero Jorge L. Tamayo titulado "Sistemas de riego en los Valles de Oaxaca” (Tamayo, 1938, pp. 37-50), en el cual se mencionaba que el tipo de obras hidráulicas en los Valles habían sido de poca importancia, ya que consistían en enramadas y bordos que desviaban el agua a las "zanjas primitivas". Para fortalecer su propuesta de pozos y presas sumergidas, Tamayo realizó una descripción somera de cómo eran utilizados las aguas superficiales de varios ríos y arroyos, aunque dejó de lado el río Atoyac en su enumeración, dándole la importancia a Tlacolula. La razón de su propuesta era que se consideraba que las aguas subterráneas eran abundantes en el valle de Tlacolula, por lo que, si se las detenía antes de que se filtraran, a través de presas sumergidas compuestas de un colector o galería filtrante, se podrían regar varios cientos de hectáreas de los pueblos. Con esta propuesta se respondía a una política federal de la Comisión Nacional de Irrigación, creada en 1926, que pretendía contar con una infraestructura adecuada para el riego y que llegara el agua a quienes no habían sido beneficiados.

Sin embargo, los procesos de homogeneización legal y tecnológicos no fueron a la par de las expectativas de aquellos que las definieron desde diversas instancias. A la par se presentaron distintos tipos de enfrentamientos entre los usuarios de una misma corriente, entre los diferentes niveles de soberanía y gobierno, pero, sobre todo, entre las distintas perspectivas locales, estatales y nacionales. Por ejemplo, una práctica constante en los valles centrales de Oaxaca fueron los arrendamientos de agua. El establecimiento de las industrias textiles y de la hidroeléctrica impactó a corto y a largo plazo en los usos y manejos del agua del río San Agustín, Valle de Etla. A su vez esto generó una serie de acuerdos y negociaciones entre los ayuntamientos, propietarios particulares y autoridades estatales que, por medio de contratos de arrendamientos y de convenios, gestionaron la administración de los recursos hídricos. En este sentido, hay que recordar que hasta finales del siglo XIX el manejo y control del agua era un asunto local y los municipios eran los encargados de celebrar los convenios, transacciones y arrendamientos.

Ante la ausencia de un gobierno central fuerte y la inexistencia de reglamentos de aguas que regularan los aprovechamientos hídricos, la distribución y el acceso al agua quedaron sujetos a los arreglos y contratos que se establecieron entre los diferentes actores locales, aunados a las prácticas cotidianas de usos del líquido. Incluso podemos agregar que, desde 1928, al menos de manera documentada, los ingenieros de la SAyF venían solicitando estudios para que se pudiera reglamentar una corriente que era compartida por diversos actores sociales. Durante ese periodo, como parte del proceso ejidal, se generó un mayor número de solicitantes del recurso hídrico. ${ }^{29}$

Los cambios tecnológicos y la diversificación de los usos del agua, aunados a la creciente inversión nacional y extranjera en la irrigación, industria, minería, hidroeléctricas, y en los sistemas de saneamiento de las ciudades, propiciaron que el ejecutivo federal se interesara por controlar y manejar los aprovechamientos hídricos, especialmente por el ingreso fiscal que supuso el cobro por los derechos de las solicitudes y concesiones de agua para compañías, particulares, ayuntamientos y estados (Aboites, Birrichaga y Garay, 2010; Aboites y Estrada 2004). Las disposiciones legales emanadas del ejecutivo federal comenzaron, de forma paulatina, a quitar las facultades que anteriormente tenían los estados y ayuntamientos para otorgar derechos para el uso de los recursos hidráulicos (Escobar O. y Sánchez, 2008). Esta situación fue aprovechada por los estados de la república mexicana para comenzar a legislar en materia de aguas. Principalmente, promulgaron leyes y decretos de alcance estatal, que disponían reglas claras en la regulación del acceso al agua, además de establecer facultades concretas para gestionar y controlar los aprovechamientos hídricos, como fue la Ley de 1905, que ya comentamos anteriormente.

\section{CONSIDERACIONES FINALES}

Como pudimos apreciar de manera breve, el ayuntamiento fue el principal interlocutor y representante de los derechos del "pueblo" frente a las instancias gubernamentales y los dueños de las haciendas. Resulta interesante observar que los argumentos de las autoridades municipales se sustentaban en la legislación 
nacional y en la estatal para obtener beneficios u oponerse a las órdenes del gobierno oaxaqueño, como en el caso de Tlacolula. La representatividad del ayuntamiento es notoria cuando paulatinamente las mismas instancias gubernamentales le quitaban, pero también le daban, una representatividad jurídica a través de la legislación estatal y de validez de la información que se generaba. No obstante, la documentación muestra que en el trasfondo del asunto existía la interpretación de la misma legislación. ${ }^{30}$ Lo que podemos apreciar es que las leyes porfirianas eran en sí leyes de jurisdicción administrativa, mas no de propiedad. En cambio, la legislación posrevolucionaria otorgaba al gobierno federal la autorización de dar derechos de propiedad, posesión, usufructo y servidumbre. En este sentido, las concesiones que tuvieron que ser refrendadas por todos los usuarios implicaron un antes y un después en el ingreso al siglo XX. Por ejemplo, las concesiones porfirianas eran únicamente de índole administrativa, alejadas de la noción de derechos privados derivados de una propiedad absoluta; posteriormente, el dominio de las aguas pasó a los gobiernos posrevolucionarios, que podían cancelar las concesiones.

Por otra parte, observamos cómo es que los distintos actores sociales interpretaron y aplicaron las leyes, tanto estatales como federales, según sus propias condiciones locales, y, al mismo tiempo, se fueron ajustando a una legislación federal cada vez más presente en la cotidianeidad. Aunque podemos decir que la permanencia de los acuerdos y negociaciones locales fue preponderante, también fue posible ajustarse al nuevo escenario político y de manejo de los recursos naturales, que dependía de los intereses de los actores sociales.

A la par de lo anterior, no debemos de dejar de lado los argumentos empleados para el acceso al agua por los ayuntamientos, los hacendados, los industriales, y algunos particulares. Estos actores sociales implementaron varias estrategias para definir sus derechos sobre los usos del agua. Uno de los mecanismos legales más concurridos fue el de apelar al reconocimiento de los derechos previamente establecidos. Dentro de estos destacan el uso del "tiempo inmemorial", los testimonios de haber utilizado el líquido de una "forma pacífica y sin interrupción”, la posesión de un título colonial o la demostración de arrendamientos previos, y los pagos de renta por el uso de las aguas -aunque hubo otros mecanismos, como validar concesiones previas, que el gobierno federal, en teoría, tendría que respetar-. De este modo, los conflictos, las negociaciones, el goce de privilegios tradicionales y la adecuación al nuevo ámbito político, donde la federación adquirió un nuevo papel, también muestran, además de la diversidad y fortaleza de los actores, que la tendencia en torno al uso del agua dependió del momento histórico en el que las prácticas sociales en torno a su acceso plantearían no solo distintos modos de usar y distribuir el líquido, sino también los derechos y la propiedad de los recursos hídricos, tanto a nivel estatal como nacional. 


\section{FIGURA 1}

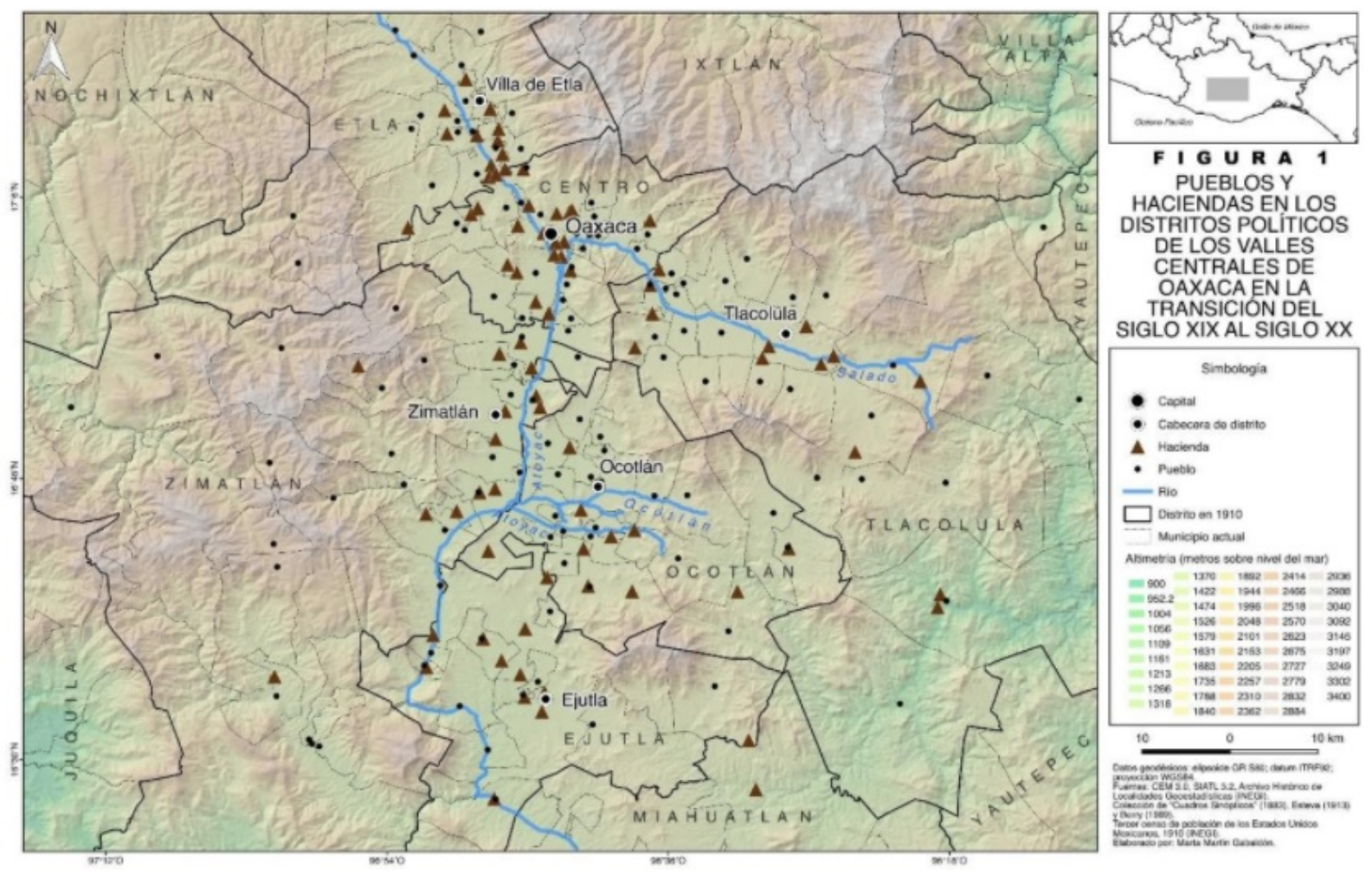

\section{REFERENCIAS}

Aboites, L. (1998). El agua de la nación: Una historia politica de México (1888-1946). México: Centro de Investigación y Estudios Superiores en Antropología Social.

Aboites, L., y Estrada, V. (Comps.) (2004). Del agua municipal al agua nacional: Materiales para una historia de los municipios en México, 1901-1945. México: Comisión Nacional del Agua, Archivo Histórico del Agua, Centro de Investigaciones y Estudios Superiores en Antropología Social y El Colegio de México.

Aboites, L., Birrichaga, D., y Garay, J. (2010). El manejo de las aguas mexicanas en el siglo XX. En B. Jiménez, M. Torregrosa y L. Aboites (ed.), El agua en México: causes y encauces (pp. 21-50). México: Academia Mexicana de Ciencias y Comisión Nacional del Agua.

Arellanes, A. (1999). Oaxaca reparto de la tierra, alcances, limitaciones y respuestas. México: PrOax, Universidad Autónoma Benito Juárez de Oaxaca, Universidad Nacional Autónoma de México y Carteles Editores.

Arellanes, A. (2008). Industria textil oaxaqueña en el Porfiriato, un panorama. En D. Traffano (Coord.), Reconocimiento al pasado: Miradas históricas sobre Oaxaca (pp. 131-166). México: Universidad Autónoma Benito Juárez de Oaxaca y Centro de Investigación y Estudios Superiores en Antropología Social.

Arrioja Díaz-Virruell, L. A. (2010). El Código Civil del estado libre de Oaxaca y su instrumentación en los espacios rurales, 1830-1835. En C. Sánchez Silva y F. J. Ruiz Cervantes (Coords. y Eds.), Código civil para gobierno del estado libre de Oajaca. Edición Facsimilar (pp. 33-47). México: Universidad Autónoma Benito Juárez de Oaxaca, Heroico Congreso del estado de Oaxaca y Secretaría de Cultural del estado de Michoacán.

Arrioja Díaz-Virruel, L. A. (2012). Conflicto por tierras y pesquisas documentales en el Valle de Oaxaca, 1912. En L. A. Arrioja y C. Sánchez (Eds.), Conflictospor la tierra en Oaxaca. De las Reformas Borbónicas a la Reforma Agraria (pp. 185-214). México: El Colegio de Michoacán y Universidad Autónoma Benito Juárez de Oaxaca.

Arrioja Díaz-Virruell, L. A., y Sánchez, C. (Eds.) (2012). Conflictos por la tierra en Oaxaca: De las reformas borbónicas a la reforma agraria. México: El Colegio de Michoacán y Universidad Autónoma Benito Juárez de Oaxaca. 
Ávila, A., Gómez, J., Escobar Ohmstede, A., Sánchez, M. (Coords.) (2009). Agua y tierra: Negociaciones, acuerdos y conflictos en México, Siglos XIX y XX. México: El Colegio de Michoacán, Centro de Investigación y Estudios Superiores en Antropología Social y Universidad Autónoma de Aguascalientes.

Barcos, M. F., Lantieri, S., y Marino, D. (Dirs.) (2017). Tierra, agua y monte: Estudios sobre derechos de propiedad en América, Europa y África (Siglos XIX y XX). Argentina: Teseo.

Birrichaga, D. (Coord.) (2007). La modernización del sistema de agua potable en México, 1810-1950. México: El Colegio Mexiquense.

Bloch, M. (1999). La tierra y el campesino. Agricultura y vida rural en los siglos XVIIy XVIII. Barcelona: Crítica Grijalvo.

Castañeda, R., Escobar Ohmstede, A., y Andrade, J. (2005). Desastre económico o debilidad federal en los primeros gobiernos posrevolucionarios. México: Archivo Histórico del Agua, Centro Nacional de las Artes, Centro de Investigaciones y Estudios Superiores en Antropología Social y Universidad Autónoma del Estado de Morelos.

Chassen-López, F. R. (2004). From Liberal to Revolutionary Oaxaca: The View from the South, México 1867-1911. EUA: University Park, Pennsylvania State University Press.

Código Civil (2010). Código civil para gobierno del estado libre de Oajaca. Edición Facsimilar. México: Universidad Autónoma Benito Juárez de Oaxaca, Heroico Congreso del estado de Oaxaca y Secretaría de Cultura del estado de Michoacán.

Comisión Nacional del Agua (2018). Actualización de la disponibilidad media anual de agua en el acuifero Valles Centrales (2025), estado de Oaxaca. México: CONAGUA.

Congost, R. (2007). Tierras, leyes, historia: Estudios sobre la gran obra de la propiedad. España: Crítica.

Contreras, J., Navarro, J., y Romero, L. (Coords.) (2015). Agua, Estado y Sociedad en América Latina y España. España: Consejo Superior de Investigaciones Científicas, Escuela de Estudios Hispano-Americanos y Asociación Cultural la Otra Andalucía.

Escobar Ohmstede, A., Sánchez, M., y Gutiérrez, A. M. (Coords.) (2008). Agua y tierra en México, siglos XIX y XX. México: El Colegio de México y El Colegio de San Luis.

Escobar Ohmstede, A., y Sánchez, M. (2008). El agua y la tierra en México, siglos XIX y XX ¿caminos separados, paralelos o entrecruzados? En A. Escobar Ohmstede, M. Sánchez y A. Gutiérrez (Coords.), Agua y tierra en México siglos XIX y XX (pp. 18-34). México: El Colegio de Michoacán y El Colegio de San Luis.

Estado (1897). Estado de Oaxaca. Contestaciones dadas al cuestionario. En Boletín de Agricultura, Minería e Industria publicado por la Secretaria de Fomento, Colonización e Industria de la República Mexicana, VI(11), 121-172.

Exposición (1904). Exposición de motivos de la ley sobre aprovechamiento de aguas públicas del Estado. Archivo General del Poder Ejecutivo del estado de Oaxaca: Fomento, legajo 19, expediente 10, México.

Fandos, C. (2017). La formación histórica de condueñazgos y copropiedades en las regiones de las Huastecas (México) y las tierras altas de Jujuy (Argentina). Hlb. Revista de Historia Iberoamericana, 10(2), 49-79.

Fernández, I., Enfield, G., y O'Hara, S. (2004). Estrategias para el control del agua en Oaxaca Colonial. Estudios de Historia Novohispana, 31, 137-198.

Garnero, G. (2017). El papel del Río de Los Sauces en la estructuración territorial de traslatierra, Córdoba (1850-1900). En M. F. Barcos, S. Lantieri y D. Marino (Dirs.), Tierra, agua y monte: Estudios sobre derechos de propiedad en América, Europa y África (Siglos XIX y XX) (pp. 71-106). Argentina: Teseo.

Gerhard, P. (1986). Geografía Histórica de la Nueva España, 1519-1821. México: Universidad Nacional Autónoma de México.

Hernández, R. (1902). Colección de leyes, circulares y otras disposiciones dictadas por el gobierno del estado de Oaxaca. México: Imprenta del estado de Oaxaca. Tomo III y VI.

Kirby, A. (1973). The Use of Land and Water Resources in the Past and Present Valley of Oaxaca. EUA: University of Michigan Press.

Lanz Cárdenas, J. T. (1982). Legislación de aguas en México. México: Gobierno del Estado de Tabasco. Tomo II.

Lees, S. (1976). Hydraulic Development and Political Response in the Valley of Oaxaca. Anthropology Quarterly, 49(3), 197-210. 
Ley de Aguas (1879). Ley de Aguas de 13 de junio de 1879: Con comentarios, referencias y notas criticas por D. Melchor de Palau Ingeniero de Caminos, Canales y Puertos y Abogado. España: Imprenta de la Renaixensa. Consultado en https://sirio.ua.es/libros/BGeografia/ley de aguas/ima0000.htm

Ley (1905). Ley de aguas del estado de Oaxaca. Exposición de motivos de la ley sobre aprovechamiento de las aguaspúblicas, 1905. Archivo General del Poder Ejecutivo del estado de Oaxaca: Fomento, legajo 19, expediente 10, México.

Lira, C. (2008). Arquitectura y sociedad: Oaxaca rumbo a la modernidad, 1790-1910. México: Universidad Autónoma Metropolitana - Azcapotzalco.

Marino, D., y Teruel, A. (2019). Reformas estatales y estructuras indígenas. Los derechos de propiedad en el México Central, el norte de Argentina y el Sur de Bolivia, 1810-1910. Boletin Americanista, LXIX(2), 79, 151-172.

Martín, M. (2018). New Crops, New Landscapes and New Socio-Political Relationships in the Cañada de Yosotiche (Mixteca Region, Oaxaca, Mexico), 16th-18th Centuries. Historia Agraria, 75, 33-68. Consultado en http:// dx.doi.org/10.26882/histagrar.075e03g

Martínez, C., y Romero, L. (Coords.) (2015). Agua e historia: Experiencias regionales, siglos XIX y XXI. México: Instituto Mora.

Mendoza, J. E. (2016a). Agua y tierra en San Gabriel Chilac, Pueblay San Juan Teotihuacán, Estado de México. México: Centro de Investigaciones y Estudios Superiores en Antropología Social.

Mendoza, J. E. (2016b). Abastecimiento de agua potable e higiene pública en la Ciudad de Oaxaca, 1867-1915. En C. Sánchez Silva (Coord.), La Ciudad de Oaxaca. Pasado, presente y futuro (pp. 325-364). México: Universidad Autónoma Benito Juárez de Oaxaca.

Mensaje (1906). Mensaje leido por el C. el Lic. Emilio Pimentel, gobernador constitucional del estado ante la XXI legislatura del mismo, y contestación del presidente del H. Congreso C. Andrés Portillo al abrir aquella su segundo periodo de sesiones ordinarias, 16 de septiembre. Oaxaca, Imprenta del Estado.

Moreno Cora, S. (1910). Ensayo Introductorio. En A. Villamar (Comp.), Las leyes federales vigentes sobre tierras, bosques, aguas, ejidos, colonización y el gran registro de la propiedad (pp. 7-78). México: Herrero Hermanos Sucesores.

Nuñez Luna, A. (2009). Las aportaciones del jurista sobre la propiedad de las aguas: del rey a la nación. En E. Kourí (Coord.), En busca de Molina Enríquez. Cien años de Los grandes problemas nacionales (pp. 127-228). México: El Colegio de México y Centro Katz, The University of Chicago.

Pérez de Yarto, A. (1894). Derecho internacional, constitucional, administrativo y civil: Estudio presentado en su examen general de abogado. México: Antigua Imprenta del Comercio.

Ponte, J. R. (2015). La cartografía hidráulica en Mendoza, Argentina (Siglos XVIII y XIX) como herramienta para historiar el espacio y espacializar la historia. Agua y Territorio, 5, 26-37. Consultado en http://dx.doi.org/10. 17561/at.v0i5.2532.

Ramírez, V. (2018). El riego en Ixmiquilpan, siglos XVIII-XX. En S. Rosas, M. Toxqui y R. Jiménez (Eds.), Usos e bistorias del agua en México: riego, ciudad y legislación (pp. 33-60). México: Benemérita Universidad Autónoma de Puebla, Instituto de Ciencias Sociales y Humanidades "Alfonso Vélez Pliego" y Ediciones del Lirio.

Reich, P. L. (2017). El derecho del agua en la Suprema Corte de Justicia de la Nación durante la época revolucionaria: 1918-1946. En J. R. Cossío Díaz (Coord.), Estudiossobre la Suprema Corte de Justicia realizados en Estados Unidos (pp. 119-158). México: Suprema Corte de Justicia de la Nación.

Rosas, S., (2018). Conflictos, debates y acuerdos por el agua en la temprana industrialización textil (El valor, Tlaxcala, 1839-1847). En S. Rosas, M. Toxqui y R. Jiménez (Eds.), Usos e historias del agua en México: riego, ciudad y legislación (pp. 115-139). México: Benemérita Universidad Autónoma de Puebla, Instituto de Ciencias Sociales y Humanidades "Alfonso Vélez Pliego" y Ediciones del Lirio.

Rosas, S., Toxqui, M., y Jiménez, R. (Eds.) (2018). Usos e historias del agua en México: riego, ciudad y legislación. México: Benemérita Universidad Autónoma de Puebla, Instituto de Ciencias Sociales y Humanidades "Alfonso Vélez Pliego" y Ediciones del Lirio.

Sánchez García, J. H. (2012). Agua y conflictos agrarios en los Valles Centrales de Oaxaca: Las disputas por el Río San Juan en el Distrito de Etla, 1905-1927. En L. A. Arrioja y C. Sánchez (Eds.), Conflictos por la tierra en Oaxaca. 
De las Reformas Borbónicas a la Reforma Agraria (pp. 215-238). México: Universidad Autónoma Benito Juárez de Oaxaca,

Sánchez García, J. H. (2013) Gobierno municipal, relaciones ciudad-campo y modernidad: Oaxaca, 1890-1912. (Tesis doctoral). El Colegio de Michoacán, Michoacán, México.

Sánchez García, J. H. (2015). La administración municipal del agua en los Valles Centrales de Oaxaca durante el Porfiriato. En J. Contreras, J. Navarro-García y S. Rosas (Coords), Agua, Estado y sociedad en América Latina y España. España: Universidad Veracruzana, Escuela de Estudios Hispano-Americanos y Coordinación de la Sociedad de la Información y el Conocimiento.

Sánchez Rodríguez, M., y Sandré, I. (2011). La administración local del agua. En I. Sandré, y M. Sánchez R. (Coords.), El eslabón perdido. Acuerdos, convenios, reglamentos y leyes locales de agua en México (1593-1935) (pp. 11-82). México: Centro de Investigaciones y Estudios Superiores en Antropología Social.

Sánchez Rodríguez, M. (2017). Del barro al tereftalato de polietileno: el oficio de aguador en México. Agua y Territorio, 9, 22-33.

Sánchez Rodríguez, M. (2018). Cuando las aguas se dividen. Control de las aguas torrenciales en México: entarquinamiento. México: El Colegio de Michoacán y CIESAS.

Secretaría de Fomento (1906). División territorial de la República Mexicana formada con los datos verificados del censo del 28 de octubre de 1900. Estado de Oaxaca. México: Imprenta y Fototipia de la Secretaría de Fomento

Secretaría de Agricultura: Dirección de Irrigación (1922). Croquis de los Valles de Etla, Tlacolula, Grandey Ejutla: Edo. de Oaxaca. Archivo Histórico del Agua: Aprovechamientos Superficiales, caja 3193, expediente 43875, México.

Tamayo, J. L. (1938). Sistemas de riego en los Valles de Oaxaca. Revista de Irrigación en México, 3(XVII), mayo-junio, 37-50.

Tanck de Estrada, D. (2005). Atlas ilustrado de los Pueblos Indígenas: Nueva España 1800. México: El colegio de México, El colegio mexiquense, Comisión de los Derechos Indígenas y Fomento Cultural Banamex.

Taylor, W. B. (1998). Terratenientes y campesinos en la Oaxaca colonial. México: Instituto Oaxaqueño de las Culturas y Fondo Estatal para la Cultura y las Artes.

Topete Pozas, O. (2015). Usos y conflictos por el agua en el Valle de Etla Oaxaca: acuerdos, contiendas y negociaciones, 1880-1930. (Tesis Doctoral). Centro de Investigaciones y Estudios Superiores en Antropología social - CDMX.

Topete Pozas, O. (2017). El proceso de adjudicación y los usos del agua en el Valle de Etla-Oaxaca a finales del siglo XIX. En A. Escobar Ohmstede, R. Falcón y M. Sánchez (Coords.), La desamortización desdeperspectivas plurales (pp. 391-423). México: El Colegio de México, Centro de Investigaciones y Estudios Superiores en Antropología Social y El Colegio de Michoacán.

Topete Pozas, O. (2018). El abasto de agua potable en la ciudad de Oaxaca de Juárez a finales del siglo XIX y principios del XX. Revista Pueblos y Fronteras Digital, 12(24), 136-162. Consultado en http://dx.doi.org/10.22201/cim sur.18704115e.2017.24.319.

Topete Pozas, O., y Méndez, A. (2019). Legislación estatal sobre los usos del agua en México: Una comparación entre los casos de Jalisco y Oaxaca, 1895-1905. Agua y territorio, 14, 57-78. Consultado en https://revistaselectron icas.ujaen.es.

Toxqui-Furlong, M. G. (2018). La concesión estatal de ríos: paso previo a su federalización. El caso de Puebla, 1883-1896. En S. Rosas, M. Toxqui y R. Jiménez (Eds.). Usos e historias (pp. 93-114). México: Benemérita Universidad Autónoma de Puebla.

Villamar, A. (Comp.) (1910). Las leyesfederales vigentes sobre tierras, bosques, aguas, ejidos, colonización y el gran registro de la propiedad. México: Herrero Hermanos Sucesores.

Wolfe, M. (2017). Watering the Revolution: An Enviromental and Technological History of Agrarian Reform in Mexico. EUA: Duke University Press. 


\section{Notas}

1 Una versión de este trabajo se elaboró en mi estancia sabática en el Instituto de Investigaciones Históricas de la UNAM, septiembre 2018-marzo 2019.

2 Véase el estudio de 1926 de Marc Bloch (1999), donde muestra la manera en que los decretos emanados en la Francia del siglo XVIII sobre cercamientos, lo común y las servidumbres colectivas respondían a realidades regionales, sin descartar las que eran elaboradas en los gabinetes gubernamentales a través de cuestionarios. La idea vertida responde a los diálogos que se manifiestan en Aboites, 1998; Birrichaga, 2007;Escobar O., Sánchez R. y Gutiérrez, 2008; Ávila, Gómez S., Escobar O. y Sánchez R., 2009; Boyer, 2012; Contreras, Navarro y Salas, 2015; Martínez y Romero, 2015; Mendoza, 2016 a y b; Cañedo y Radding, 2016; Wolfe, 2017; Rosas, Toxqui y Jiménez, 2018; Topete y Méndez, 2019, pp. 57-68, que en su mayoría consideran la imposición de lo jurídico desde "arriba" (Estado) con algunas respuestas de los posibles afectados.

3 Por ejemplo, la comparación entre Oaxaca y Jalisco (México) en Topete y Méndez, 2019, pp. 57-68; en relación a Argentina y México véase Fandos, 2017, pp. 49-79. Sobre Argentina, Bolivia y México a Marino y Teruel, 2019, pp. 151-172.

4 Algunos de los más significativos pueden verse en la nota 2 de este artículo.

5 Deseamos resaltar algunas de las investigaciones con perspectivas históricas, que, para el caso que nos atañe, se generaron con mayor fuerza a partir de los años 1970, como los de Kirby, 1973 y Lees, 1976, pp. 197-210. Su objetivo era analizar cómo se daban los cambios en "comunidades corporativas cerradas" a partir de sus relaciones con "unidades" a nivel nacional, aspecto que no consideramos en este trabajo.

6 Archivo Histórico del Agua, Aprovechamientos Superficiales (AHA, AS), Caja 2748, exp. 38478, abril de 1928.

7 Archivo General del Poder Ejecutivo del estado de Oaxaca, Fomento (AGEPEO, F), Legajo 10, exp. $25,1909$.

8 Entre paréntesis pondremos el valle o distrito al que pertenecen las haciendas, pueblos, rancherías o molinos.

9 Archivo General del Poder Ejecutivo del estado de Oaxaca, Asuntos Agrarios, Administración IV (AGEPEO, AAAIV), Legajo 884 (01), exp. 20, 1927.

10 AHA, AS, Caja 944, exp. 13365, 1924.

11 Centro académico y cultural San Pablo, Biblioteca fray Juan de Córdova (CACSP, BFJC), Colección Luis Castañeda Guzmán, Sección civil, Serie haciendas, Caja 28, 1919-1922.

12 Se considera que "lo cierto es que la realidad oaxaqueña era más compleja, es decir, desde la Colonia hasta la República, los indios y los no indios que radicaban en las villas y en los pueblos se distinguieron por conducirse hábilmente entre la maraña de leyes y juzgados con el objeto de resolver sus diferencias, reivindicar sus derechos y plantear sus demandas ante el Estado" (Arrioja, 2010, p. 37), y se concluye que "el código civil oaxaqueño no solo se instrumentó en las áreas rurales de Oaxaca, sino también fue del conocimiento del grueso de la población indígena” (Arrioja, 2010, p. 48). Habría que considerar en qué términos y de qué manera era del "conocimiento del grueso de la población".

13 AHA, AS, Caja 2795, exp. 39118, septiembre de 1924.

14 AGEPEO, F., Legajo 24, exp. 16, 1911-1912; AGEPEO, F., Legajo 9 exp. 9, 1903.

15 Los Reglamentos son una forma de injerencia del ayuntamiento en la gestión del recurso hídrico aun cuando se encontraba bajo la supervisión de las autoridades estatales, como en el caso de Sonora y Zacatecas en la quinta y séptima década del siglo XIX (Sánchez R. y Sandré, 2011, pp. 39-43). Pareciese que no se realizaron los reglamentos en el caso de Oaxaca, al menos así lo deja entrever el presidente municipal de San Juan Guelache (Distrito de Etla), al mencionar, en 1912, que no se contaba con reglamento, pero que con base en la "costumbre" se cobraba igual en el día que en la noche, pero conforme el líquido comenzaba a escasear se incrementaba el precio de manera sustancial. AGEPEO, F., Legajo 24, exp. 16.

16 AHA, AS, Caja 358, exp. 7298, 1888-1926.

17 En la exposición y justificación la Comisión del Congreso de Oaxaca reiteraba, al menos unas cinco veces, que tomaban algunos aspectos de la ley del 13 de junio de 1879 sobre aguas de España (sustituía a la del 3 agosto de 1866). Sin embargo, se puntualizó que el primer capítulo se tomó de la ley española, así como los capítulos 2 y 3 , solo que al tercero se le agregó lo de las servidumbres. Asimismo, para reglamentar el uso y aprovechamiento de aguas públicas se utilizó la división de la ley española de aprovechamiento de “comunes y especiales”. AGEPEO, F., Legajo 19, exp. 10, también véase Sánchez R. y Sandre, 2011, pp. 261-285.

18 Aspecto que era constante, no solo en México, sino también en otras partes de Latinoamérica; por ejemplo, en el caso de Córdoba (Argentina) la utilización de convenios y acuerdos entre las municipalidades y los usuarios fue una constante y en donde el gobierno provincial jugaba un rol esencial de negociación (Garnero, 2017, pp. 71-106; Ponte, 2015 , pp. 26-37). Para el caso de México consúltese (Ramírez, 2018, pp. 33-60; Toxqui-Furlong, 2018, pp. 93-113; Rosas, 2018, pp. 115-149). 
19 Lo que también entraba en contradicción con la Ley del 4 de junio de 1894 que había facultado al gobierno federal para concesionar las aguas a particulares, fuera para riego o para "potencia". (Villamar, 1910).

20 Archivo General del Poder Ejecutivo del estado de Oaxaca, Conflicto por límites (AGEPEO, CL), Legajo 57, exp. 3, 1910. Sánchez G., 2012, 215-238; Topete, 2017, 391-423.

21 AGEPEO, F., Legajo 22, exp. 1, 1906-1907 y legajo 24, exp. 16, 1911-1912.

22 Casa de la Cultura Jurídica de Oaxaca (CCJO), Juzgado del 1er. Distrito, Amparo, exp. 79/925

23 El 25 de abril de 1932 el ayuntamiento de Tlacolula, en sesión ordinaria, solicitó a la Secretaría de Agricultura y Fomento la concesión el río Salado para uso público y doméstico. Este aspecto iba ligado a un decreto nacional del 31 de julio de 1932 en que se consideraba que los ayuntamientos contaban con personalidad para solicitar la confirmación o concesión para aprovechar las aguas de los ríos de propiedad nacional. AHA, AS, Caja. 2032, exp. 30657, 1932; véase también AGEPEO, AAAIV, Legajo 891 (08), exps. 5 y 6, 1931-1932; AGEPEO, F., Legajo 9, exp. 9, 1903 y legajo 23, exp. 6, 1907.

24 AHA, AS, Caja 2749, exp. 38508, 1918-1922.

25 AHA, AS, Caja 270, exp. 6508, 1917-1924. En agosto de 1918 el síndico municipal y 145 vecinos se ampararon en contra de actos del gobierno estatal por la supuesta orden de destruir las obras que se encontraban en el río Salado y que servían para la irrigación. AHA, AS, Caja 2749, exp. 38508, 1907-1928.

26 Archivo General del Poder Ejecutivo del estado de Oaxaca, Gobierno de los Distritos (AGEPEO, GD), legajo 4, exp. 40.

27 AGEPEO, AAAIV, Legajo 884 (01), exp. 19, 1923.

28 AGEPEO, AAAIV, Legajo 885(2), exp. 5. El 1 de marzo de 1932 la Comisión Nacional Agraria había decidido que, en torno a la accesión de aguas, lo que correspondía a cada ejido en relación a aguas no constantes no se midiera en metros cúbicos sino a través de tandeos. AGEPEO, AAAIV, Legajo 885(2), exp. 4, 1930-1933

29 El septiembre de 1943 la SAyF informaba que aún no había un reglamento, por lo que los interesados en torno al agua deberían ser "validados" por el ayuntamiento, aun cuando este no estuviera capacitado para dar concesiones de aguas para riego. AHA, AS, Caja 2744, exp. 38428, 1940-1943.

30 Moreno Cora (1910, p. 335 y ss), en su estudio introductorio a Las leyesfederales, considera que en 1892 fue cuestionada la ley de 1888, ya que solo los ríos federales podían ser concesionadas no todas las aguas. 